\title{
A diagnostic approach for defining idiopathic remitting diabetes: a retrospective cohort study
}

\author{
Tarig Babiker ${ }^{1,2}$, Ali J Chakera ${ }^{1,2}$, Maggie Shepherd ${ }^{1,2}$ and Andrew T Hattersley ${ }^{1,2^{*}}$
}

\begin{abstract}
Background: 11 patients were referred to our Molecular Genetics Department at the Royal Devon and Exeter Hospital between 2000-2012 with a physician's diagnosis of remitting diabetes. Our aim was to identify patients with remitting diabetes whose clinical presentation is not explained by any known aetiology of diabetes.

Methods: We obtained longitudinal clinical data on all 11 patients from the hospital records. All patients were aged between 0.5 and 35 years at diagnosis. We applied clinical criteria derived from the literature to establish 1) definite diabetes, 2) diabetes initially severe-requiring treatment with insulin, 3) remission of diabetes, and 4) exclusion of known causes of remitting diabetes.
\end{abstract}

Results: 10 out of 11 patients had an alternative explanation for their remission or a clear diagnosis was not identified. We identified a single patient with idiopathic remitting diabetes using these criteria. The patient was a white Caucasian female diagnosed aged 15 with symptoms of diabetes, laboratory glucose of $21.2 \mathrm{mmol} / \mathrm{L}$ and $\mathrm{HbA1c} 134 \mathrm{mmol} / \mathrm{mol}$. Her BMl was $23.6 \mathrm{~kg} / \mathrm{m}^{2}$. She was treated with basal bolus insulin but discontinued two years after diagnosis due to hypoglycaemia. 13 years post diagnosis, she had a normal oral glucose tolerance test during pregnancy (fasting glucose $4.5 \mathrm{mmol} / \mathrm{L}, 2 \mathrm{hr}$ glucose $4.8 \mathrm{mmol} / \mathrm{L}$ ) and an $\mathrm{HbA1c}$ of $30 \mathrm{mmol} / \mathrm{mol}$. This patient does not appear to have Type 1 or Type 2 diabetes, and furthermore does not fit into current classifications of diabetes.

Conclusions: Idiopathic remitting diabetes is rare but does exist. Strict clinical criteria are important to ensure patients have a robust clinical diagnosis. Identification of more patients with idiopathic remitting diabetes will enable further study of the clinical course of this syndrome. Applying these strict criteria will allow the identification of patients with remitting diabetes to assess its aetiology.

Keywords: Diabetes, Remission, Criteria, Diagnosis, Remitting diabetes

\section{Background}

Diabetes is a heterogeneous disease that can occasionally remit. In the majority of remitting cases a cause can be identified. Examples include patients with Type 2 diabetes who lose weight through severe caloric restriction [1] or have had gastric bypass surgery [2], those with Type 1 diabetes who are in the honeymoon period [3], transient neonatal diabetes due to a methylation abnormality in chromosome 6q24 [4], and patients of African or Hispanic origin with ketosis-prone diabetes [5]. Rarely, patients initially assumed to have Type 1 diabetes have managed to

\footnotetext{
* Correspondence: A.T.Hattersley@exeter.ac.uk

'Department of Diabetes and Endocrinology, Royal Devon and Exeter NHS Foundation Trust, Exeter, UK

${ }^{2}$ NIHR Exeter Clinical Research Facility, University of Exeter Medical School, Barrack Road, Exeter EX2 5DW, UK
}

\section{Ciomed Central}

maintain euglycaemia without treatment and have stopped using insulin for longer than would be expected of the honeymoon period [6]. This appears to be a unique form of diabetes that does not fit into the current classification of diabetes [7] and needs to be differentiated from other types.

If we could identify patients with idiopathic remitting diabetes, we would have an opportunity to study these patients to establish the cause of their diabetes and why it remits. At present there are no distinguishing clinical criteria to differentiate idiopathic remitting diabetes from other forms of diabetes.

Our aim was to identify patients with idiopathic remitting diabetes using robust clinical criteria. We systematically 
analysed patients referred to our centre with a diagnosis of "remitting diabetes" and applied literature-derived clinical criteria to exclude other forms of diabetes where remission can occur.

\section{Methods \\ Subjects}

We searched all referrals to our centre at the University of Exeter Medical School Clinical Research Facility ( $\mathrm{n}>$ 15,000) between 2000 - 2012 for patients with a physician's diagnosis of remitting diabetes, diagnosed between the ages of $0.5-35$ years using the search terms remit, remit*, remis* in the database of referrals, excluding the 2 patients we have previously described [6].

\section{Data collection}

We gathered longitudinal data from patients' clinical records. We established patients' clinical characteristics age of diagnosis, ethnic origin, body mass index, mode of treatment, duration of treatment with insulin and how long they had been in remission. In addition we determined $\mathrm{HbA} 1 \mathrm{c}$ and/or laboratory glucose at diagnosis and in remission, C-peptide or urinary C-peptide/creatinine ratio, and GAD/IA2 autoantibodies.

\section{Criteria}

We then applied criteria to this cohort of 11 patients that defined patients with a definite diagnosis of diabetes, initial severe diabetes - requiring treatment with insulin, definite remission, and excluded other forms of diabetes that can remit in order to find patients with true idiopathic remitting diabetes. These criteria were derived from studies in the literature.

Diagnostic Criteria for Idiopathic Remitting Diabetes:

-Aged over 6 months or less than 35 years at diagnosis

-White Caucasian

-HbA1c laboratory glucose diagnostic of diabetes

-BMI less than $30 \mathrm{~kg} / \mathrm{m}^{2}$

-Marked fasting hyperglycaemia (to exclude

glucokinase-MODY) and requiring treatment with

insulin from diagnosis
-4 consecutive years without insulin treatment and

$\mathrm{HbA1c}$ in the normal range

-Other forms of remitting diabetes excluded (Table 1)

\section{Definite diagnosis of diabetes}

Patients should have a definite biochemical diagnosis of diabetes. We used WHO criteria based either on glucose (random glucose greater than $11.1 \mathrm{mmol} / \mathrm{L}$ with symptoms suggestive of diabetes, fasting glucose greater than $7.0 \mathrm{mmol} / \mathrm{L}$, or a 2 hour glucose greater than $11.1 \mathrm{mmol} / \mathrm{L}$ ) [8] or $\mathrm{HbA} 1 \mathrm{c} \geq 6.5 \%(48 \mathrm{mmol} / \mathrm{mol})$ [9].

\section{Diabetes initially severe - requiring treatment with insulin}

Treatment is a marker of the severity of initial hyperglycaemia especially in young patients diagnosed before 35 years of age. We wanted there to be clear remission from initially marked hyperglycaemia. A patient requiring treatment with insulin from diagnosis is more likely to have marked hyperglycaemia and less likely to have Type 2 diabetes [10].

\section{Definite remission}

To have clear remission the patients should be able to stop all diabetes treatment and have normal glucose tolerance $(\mathrm{HbA} 1 \mathrm{c}<6.5 \% / 48 \mathrm{mmol} / \mathrm{mol})$. Type 1 diabetes is associated with a honeymoon period where insulin secretion is improved. This can lead to remission although most patients continue to take some insulin.

A period of remission of greater than 4 years is unusual for the honeymoon period. Previous studies have shown that $10 \%$ of patients with Type 1 diabetes are off insulin 12 months after initially commencing insulin [11]. Another study defined remission as an insulin dose of $\leq 0.3$ units $/ \mathrm{kg} /$ day with an $\mathrm{HbA1c}$ in the normal range, and found a prevalence of duration of remission of greater than 4 years of $2.5 \%$ in a sample of 362 patients [12].

We used a stricter definition of remission as defined by withdrawal of all treatment for diabetes for 4 years, with an $\mathrm{HbA} 1 \mathrm{c}<6.5 \%$ ( $48 \mathrm{mmol} / \mathrm{mol})$ during this period.

Table 1 Known types of remitting diabetes and the criteria applied to define them

\begin{tabular}{ll}
\hline Recognised forms of remitting diabetes & Defining criteria \\
\hline Type 1 diabetes in the honeymoon period & GAD/IA2 positive \\
& Remission within four years of diagnosis \\
Type 2 diabetes with weight loss & Obesity at diagnosis with subsequent weight loss or bariatric surgery \\
Transient neonatal diabetes & Diabetes diagnosed under 6 months of age \\
Ketosis-prone atypical diabetes & Non-Caucasian \\
Stress induced hyperglycaemia or steroid-induced hyperglycaemia & Diagnosed at a time of extreme physiological stress e.g. acute illness \\
& Concurrent glucocorticoid use around the time of diagnosis \\
\hline
\end{tabular}




\section{Other forms of diabetes excluded}

Our criteria excluded patients with a BMI above $30 \mathrm{~kg} / \mathrm{m}^{2}$ who are those more likely to have Type 2 diabetes [13]. In obese patients any remission may be due to increased insulin sensitivity after weight loss [1]. Our patients were aged between 6 months and 35 years. An age over 6 months excludes transient neonatal diabetes [4] and an age at diagnosis of greater than 35 years is used by the Royal College of General Practitioners to identify patients more likely to have Type 2 diabetes [14]. Patients of non-European ancestry may have ketosis-prone diabetes, a form of diabetes that can remit $[5,15,16]$, and so our criteria only includes patients of White European ancestry. We also excluded patients with stress hyperglycaemia [17] i.e. due to acute illness or those with hyperglycaemia secondary to corticosteroid use [18].

We thus defined idiopathic remitting diabetes as a nonobese, White European patient aged between 6 months and 35 years with a clear documented diagnosis of diabetes, treated with insulin from diagnosis, who had not required treatment for a period of 4 years or longer, with an HbA1c in the normal range when in remission, not on corticosteroids at the time of diagnosis.

\section{Results}

\section{Most patients had an alternative reason for remission}

We identified 11 patients referred with remitting diabetes. Our diagnostic criteria excluded 10 out of the 11 patients (Figure 1). All our patients were White European, aged less than 35 years at diagnosis, but none aged less than 6 months. 2 patients did not have a confirmed diagnosis of diabetes mellitus, one of the patients having only a capillary glucose value but no laboratory glucose or HbA1c. In total, 3 patients had a possible diagnosis of type 2 diabetes; 2 patients with a BMI above $30 \mathrm{~kg} / \mathrm{m}^{2}$ and 1 patient treated with oral hypoglycaemic agents from diagnosis. 1 patient had a transient hyperglycaemia after a course of oral steroids.

\section{1 patient had true idiopathic remitting diabetes}

Application of our diagnostic criteria identified one patient with idiopathic remitting diabetes (Figure 1). This was a female patient diagnosed aged 15, after presenting with symptomatic diabetes and a period of rapid weight loss of approximately $12-15 \mathrm{~kg}$ over 2.5 months. Her laboratory glucose at diagnosis was $23 \mathrm{mmol} / \mathrm{L}$ and $\mathrm{HbA} 1 \mathrm{c}$ was $14.4 \%$ (134 mmol $/ \mathrm{mol})$. Her BMI was $23.6 \mathrm{~kg} / \mathrm{m}^{2}$. She was commenced on basal bolus insulin and remained on treatment for two years. She then stopped treatment due to hypoglycaemia; her $\mathrm{HbA} 1 \mathrm{c}$ was $5.4 \%(36 \mathrm{mmol} / \mathrm{mol})$. She had an oral glucose tolerance test aged 28 (fasting glucose $4.5 \mathrm{mmol} / \mathrm{L}, 2$ hour glucose $4.8 \mathrm{mmol} / \mathrm{L}$ ) during pregnancy. She has remained off treatment to date. There was no significant weight loss in the 15 years post- diagnosis making insulin resistance unlikely. GAD, IA2 and ZnT8 antibodies were negative, and she had preserved C-peptide with a UCPCR $9.98 \mathrm{nmol} / \mathrm{mol}$ (5th and 95th percentiles for non-diabetic controls $0.58 \mathrm{mmol} / \mathrm{mol}$ and $10.37 \mathrm{mmol} / \mathrm{mol}$ respectively) [19]. She has a family history of diabetes, with a maternal grandmother diagnosed with Type 2 diabetes, and a paternal uncle with Type 1 diabetes diagnosed in his teens. Neither parent has had diabetes. She has no siblings but her son, currently aged 3, does not have diabetes. Targeted next-generation sequencing of the 29 genes known to cause monogenic diabetes has not identified a mutation [20]. Her case does not fit in with any of the known causes of diabetes that remit. According to our criteria, the patient has idiopathic remitting diabetes, with her remission lasting even during pregnancy.

\section{Discussion}

\section{Idiopathic remitting diabetes is rare}

We have identified a cause for remission in 10 out of 11 patients with a physician's diagnosis of remitting diabetes. Patients were either misdiagnosed or had another possible cause for their remitting hyperglycaemia. We identified a single patient with idiopathic remitting diabetes, on insulin for 2 years post diagnosis, and then remitting and remaining off treatment for the following 15 years, even during pregnancy. Idiopathic remitting diabetes is rare, as we have identified a single case from a database of $>15,000$ patients. Remitting diabetes of a similar pattern has been described by our group previously, affecting two young sibling boys of European ancestry [6]. We have not found any other cases in the literature.

\section{Strict criteria are necessary to identify patients who may have another cause for remission}

Strict criteria have identified only 1 patient with idiopathic remitting diabetes. It may be that within our cohort of patients there are other patients with the same disease process who have not been identified due to the strict nature of our criteria. Inclusion of patients with a BMI above $30 \mathrm{~kg} / \mathrm{m}^{2}$, for example, may yield a larger number of patients with idiopathic remitting diabetes, although as the average population BMI is increasing, there are likely to be more patients with Type 2 diabetes. However, it is only through using such strict criteria that we can be sure that there is not an alternative form of diabetes until more patients have been identified and studied to establish improved criteria, perhaps including other clinical characteristics, biomarkers or genetic testing.

\section{Case discussion}

\section{Remitting diabetes vs Type 1 diabetes}

Our patient with idiopathic remitting diabetes does not have typical Type 1 diabetes. The prolonged length of 


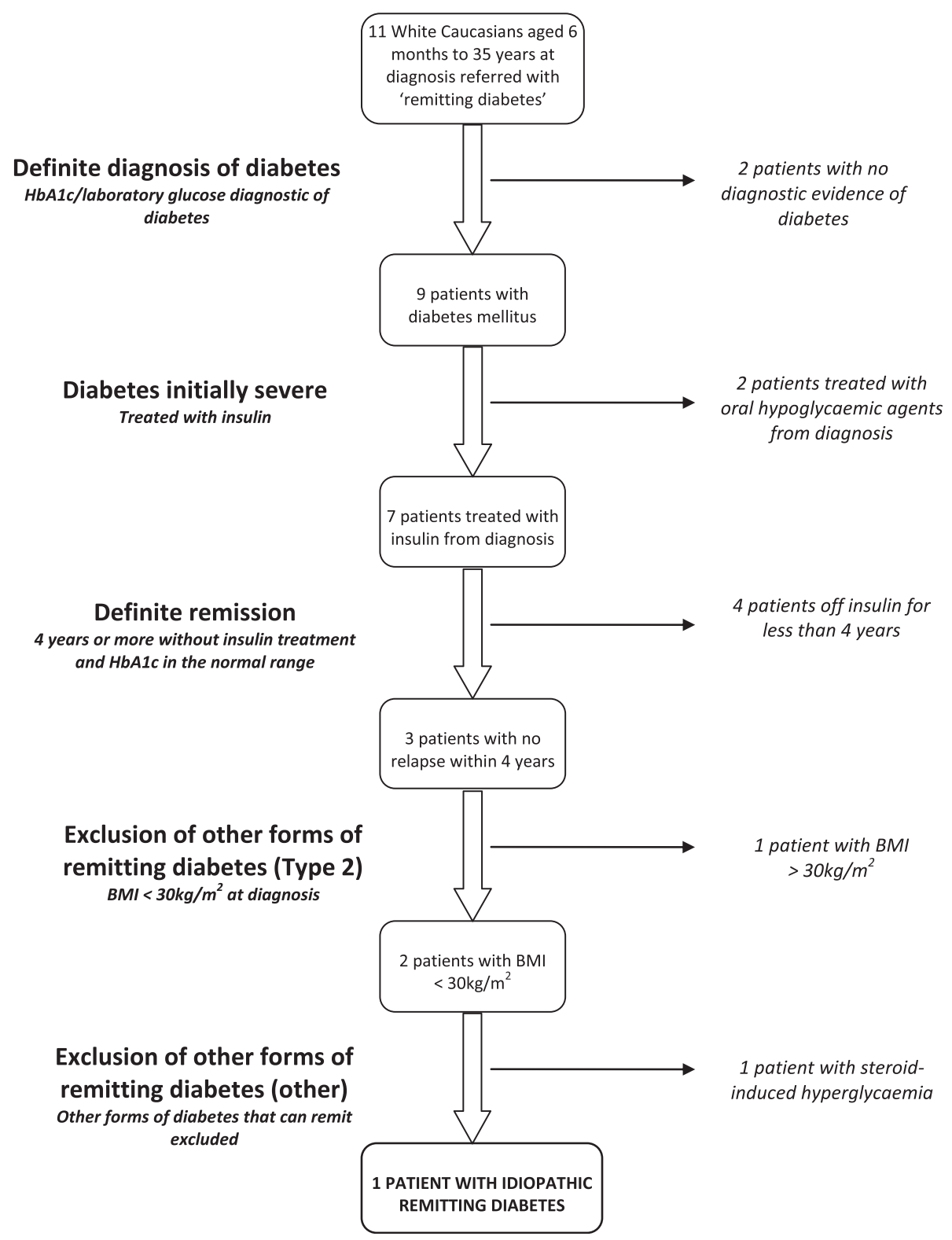

Figure 1 Flow chart showing referrals and the application of diagnostic criteria to diagnose idiopathic remitting diabetes.

time without insulin is not consistent with Type 1 diabetes in the honeymoon period. Whilst the honeymoon period is a common phenomenon in Type 1 diabetes, it is rare that it would continue for longer than 4 years and virtually all patients in a Swedish study looking at the length or remission after an initial diagnosis of Type 1 diabetes needed insulin therapy within this time period [12]. Our patient had preserved C-peptide secretion 13 years after her initial diagnosis of diabetes. This suggests that beta cell function was only temporarily disrupted. Previous work has demonstrated that patients this many years after a diagnosis of Type 1 diabetes are unlikely to be producing endogenous insulin in such quantities [21]. In addition, our patient has not developed diabetic ketoacidosis in the 15 years of her remission despite no insulin treatment. Negative GAD and IA2 antibodies also support that this is unlikely to be Type 1 diabetes [22]. The previous case report has also not identified insulin, islet cell or GAD autoantibodies in these patients [6].

\section{Remitting diabetes vs Type 2 diabetes}

This is not likely to be Type 2 diabetes in remission as our patient had a normal BMI at diagnosis in her teens. It is unusual to have an insulin requirement for 2 years after initial presentation before developing insulin independence in the 
absence of weight loss. Pregnancy is a period of heightened insulin resistance, and patients with risk factors may develop gestational diabetes [23]. Our patient has not relapsed, even after 13 years without insulin treatment and has even had normal glucose tolerance in pregnancy.

\section{Rare forms of diabetes that can remit}

The manner in which our patient's diabetes progressed does not fit with glucokinase-MODY. Patients with glucokinase-MODY can be mistaken for having diabetes and can have an HbAlc in the diagnostic range [24]. These patients are often initially treated with insulin (perhaps due to their young age at diagnosis), then stop treatment due to perceived improvement in $\mathrm{HbA1c}$ and therefore appear to remit. HbA1c incorrectly diagnoses more patients who have glucokinase-MODY with diabetes compared with fasting glucose [24]. We have excluded glucokinase-MODY as our patient had markedly high initial glucose values which are now normal, evidenced also by the normal fasting glucose values our patient had in her OGTT in pregnancy (lower fasting glucose than seen in glucokinase-MODY [25]).

Ketosis-prone diabetes is another form of diabetes that can appear to remit, with patients developing episodes of acute hyperglycaemia and ketosis, requiring insulin and intermittent periods with no insulin-dependence [5]. Patients with remitting diabetes should be of white Caucasian ancestry to distinguish them from a possible diagnosis of ketosis-prone diabetes, which is well described in patients of non-Caucasian ancestry [16].

\section{Aetiology of idiopathic remitting diabetes}

It is clear that more research is needed to establish the biology of this form of diabetes. Whilst it is difficult to establish an aetiology with so few cases described, it could be that it is due to a transient viral illness, or a burnt out autoimmune process which has been seen in other autoimmune conditions such as juvenile idiopathic arthritis [26] and membranous glomerulonephritis [27]. One theory postulates that Type 1 diabetes is a relapsing-remitting disease process with an interplay of autoreactive effector $\mathrm{T}$ cells and regulatory $\mathrm{T}$ cells dictating whether diabetes progresses or remits [28]. Parallels can also be drawn with multiple sclerosis, some patients having a single episode, others relapsing several times, and others with a primary progressive disease pattern [29]. An age of diagnosis greater than 6 months excludes transient neonatal diabetes, but this may be an area to look for comparisons in further research. Further exome sequencing of family members could uncover an as of yet undiscovered genetic cause, however given the absence of diabetes in the patient and her first degree relatives, this seems inappropriate.

\section{Limitations of the study}

We have relied on data from clinical records which may be inaccurate or incomplete despite confirmation from hospital laboratories.

There are limitations to the way in which our criteria have been applied. Using strict criteria means that we may have excluded patients who may genuinely have idiopathic remitting diabetes, but given our data may be incomplete in some cases, using strict criteria is essential.

\section{Conclusion}

It is unclear at present what the natural history, rate of complications, risk of relapse and aetiology is in patients with idiopathic remitting diabetes. More patients will need to be identified in order to study this further. In order to do this, we have found that identifying Remitting Diabetes of unknown aetiology requires the application of strict clinical criteria.

\section{Ethics statement}

This study was not deemed to require REC approval under GAfREC guidelines as it involved research undertaken by staff within a care team using information previously collected in the course of care for their own patients or clients, which was pseudonymised in conducting the research.

\section{Competing interests}

All authors' declare that they have no competing interests.

\section{Authors' contributions}

All authors made substantial contributions to conception and design, acquisition of data, or analysis and interpretation of data. In addition, all authors were involved in drafting the article or revising it critically for important intellectual content and final approval of the version to be published. Any unpublished clinical data is held on our clinical database available to colleagues at the NIHR Exeter Clinical Research Facility only.

\section{Acknowledgements}

This paper presents independent research supported by the National Institute for Health Research (NIHR) Exeter Clinical Research Facility. The views expressed are those of the author(s) and not necessarily those of the NHS, the NIHR or the Department of Health.

With thanks to Dr E C Crowne for providing clinical details on our patient with remitting diabetes.

\section{Funding}

This research received no specific grant from any funding agency in the public, commercial or not-for-profit sectors.

Received: 24 September 2013 Accepted: 28 May 2014

Published: 9 June 2014

\section{References}

1. Lim E, Hollingsworth K, Aribisala B, Chen M, Mathers J, Taylor R: Reversal of type 2 diabetes: normalisation of beta cell function in association with decreased pancreas and liver triacylglycerol. Diabetologia 2011, 54(10):2506-2514.

2. Arterburn DE, Bogart A, Sherwood NE, Sidney S, Coleman KJ, Haneuse S, O'Connor PJ, Theis MK, Campos GM, McCulloch D: A multisite study of long-term remission and relapse of type 2 diabetes mellitus following gastric bypass. Obes Surg 2013, 23(1):93-102. 
3. Abdul-Rasoul M, Habib H, Al-Khouly M: The honeymoon phase'in children with type 1 diabetes mellitus: frequency, duration, and influential factors. Pediatr Diabetes 2006, 7(2):101-107.

4. Flanagan SE, Patch A-M, Mackay DJ, Edghill EL, Gloyn AL, Robinson D, Shield JP, Temple K, Ellard S, Hattersley AT: Mutations in ATP-sensitive K+ channel genes cause transient neonatal diabetes and permanent diabetes in childhood or adulthood. Diabetes 2007, 56(7):1930-1937.

5. Winter WE, Maclaren NK, Riley WJ, Clarke DW, Kappy MS, Spillar RP: Maturity-onset diabetes of youth in black Americans. N Engl J Med 1987, 316(6):285-291.

6. Burren $\mathrm{CP}$, Hattersley AT: Remitting Diabetes A new genetic subgroup? Diabetes Care 2004, 27(7):1836-1836.

7. American Diabetes Association: Diagnosis and classification of diabetes mellitus. Diabetes Care 2012, 35(Suppl 1):S64-71.

8. World Health Organization: Definition, diagnosis and classification of diabetes mellitus and its complications. World Health Organization; 1999 [http:// whalibdoc.who.int/hq/1999/who_ncd_ncs_99.2.pdf] (accessed 04.03.13).

9. World Health Organization: Use of glycated haemoglobin ( $\mathrm{HbAlc}$ ) in the diagnosis of diabetes mellitus. Geneva (Switzerland): The Organization; 2011

10. Zimmet P, Turner R, McCarty D, Rowley M, Mackay I: Crucial points at diagnosis. Type 2 diabetes or slow type 1 diabetes. Diabetes Care 1999, 22:B59-64.

11. Schölin A, Berne C, Schvarcz E, Karlsson FA, Björk E: Factors predicting clinical remission in adult patients with type 1 diabetes. $J$ Intern Med 1999, 245(2):155-162.

12. Schölin A, Törn C, Nyström L, Berne C, Arnqvist H, Blohmé G, Bolinder J, Eriksson J, Kockum I, Landin-Olsson M: Normal weight promotes remission and low number of islet antibodies prolong the duration of remission in type 1 diabetes. Diabet Med 2004, 21(5):447-455.

13. Kahn SE, Hull RL, Utzschneider KM: Mechanisms linking obesity to insulin resistance and type 2 diabetes. Nature 2006, 444(7121):840-846.

14. Royal College of General Practitioners: Coding, classification and diagnosis of diabetes: A review of the coding, classification and diagnosis of diabetes in primary care in England with recommendations for improvement. NHS Diab, Newcastle Tyne 2011, http://www.diabetes.nhs.uk/ document.php?o=208 (accessed 04.03.13).

15. Mauvais-Jarvis F, Sobngwi E, Porcher R, Riveline J-P, Kevorkian J-P, Vaisse C, Charpentier G, Guillausseau P-J, Vexiau P, Gautier J-F: Ketosis-Prone Type 2 Diabetes in Patients of Sub-Saharan African Origin Clinical Pathophysiology and Natural History of $\beta$-Cell Dysfunction and Insulin Resistance. Diabetes 2004, 53(3):645-653.

16. Umpierrez GE, Smiley D, Kitabchi AE: Narrative review: ketosis-prone type 2 diabetes mellitus. Ann Int Med 2006, 144(5):350-357.

17. Dungan KM, Braithwaite SS, Preiser J-C: Stress hyperglycaemia. Lancet 2009, 373(9677):1798-1807.

18. Clore JN, Thurby-Hay L: Glucocorticoid-induced hyperglycemia. Endocr Pract 2009, 15(5):469-474.

19. Diabetes Genes. [http://diabetesgenes.org/content/urine-c-peptidecreatinine-ratio] (accessed 04.03.13).

20. Ellard S, Allen HL, De Franco E, Flanagan S, Hysenaj G, Colclough K, Houghton J, Shepherd M, Hattersley A, Weedon M: Improved genetic testing for monogenic diabetes using targeted next-generation sequencing. Diabetologia 2013, 56(9):1958-1963.

21. Palmer JP, Fleming GA, Greenbaum CJ, Herold KC, Jansa LD, Kolb H, Lachin JM, Polonsky KS, Pozzilli P, Skyler JS: C-Peptide Is the Appropriate Outcome Measure for Type 1 Diabetes Clinical Trials to Preserve $\beta$-Cell Function Report of an ADA Workshop, 21-22 October 2001. Diabetes 2004, 53(1):250-264.

22. Verge CF, Stenger D, Bonifacio E, Colman PG, Pilcher C, Bingley PJ, Eisenbarth G: Combined use of autoantibodies (IA-2 autoantibody, GAD autoantibody, insulin autoantibody, cytoplasmic islet cell antibodies) in type 1 diabetes: Combinatorial Islet Autoantibody Workshop. Diabetes 1998, 47(12):1857-1866.

23. Ryan EA, Enns L: Role of gestational hormones in the induction of insulin resistance. J Clin Endocrinol Metab 1988, 67(2):341-347.

24. Steele AM, Wensley KJ, Ellard S, Murphy R, Shepherd M, Colclough K Hattersley AT, Shields BM: Use of HbA1c in the Identification of Patients with Hyperglycaemia Caused by a Glucokinase Mutation: Observational Case Control Studies. PLoS One 2013, 8(6):e65326.

25. Stride A, Vaxillaire M, Tuomi T, Barbetti F, Njølstad P, Hansen T, Costa A, Conget I, Pedersen O, Søvik O: The genetic abnormality in the beta cell determines the response to an oral glucose load. Diabetologia 2002, 45(3):427-435.

26. Wallace CA, Huang B, Bandeira M, Ravelli A, Giannini EH: Patterns of clinical remission in select categories of juvenile idiopathic arthritis. Arthritis Rheum 2005, 52(11):3554-3562.

27. Polanco N, Gutiérrez E, Covarsí A, Ariza F, Carreño A, Vigil A, Baltar J, Fernández-Fresnedo G, Martín C, Pons S: Spontaneous remission of nephrotic syndrome in idiopathic membranous nephropathy. J Am Soc Nephrol 2010, 21(4):697-704.

28. von Herrath M, Sanda S, Herold K: Type 1 diabetes as a relapsingremitting disease? Nat Rev Immunol 2007, 7(12):988-994.

29. Weinshenker B, Bass B, Rice G, Noseworthy J, Carriere W, Baskerville J, Ebers $\mathrm{G}$ : The natural history of multiple sclerosis: a geographically based study I. Clinical course and disability. Brain 1989, 112(1):133-146.

doi:10.1186/1472-6823-14-45

Cite this article as: Babiker et al:: A diagnostic approach for defining idiopathic remitting diabetes: a retrospective cohort study. BMC Endocrine Disorders 2014 14:45.

\section{Submit your next manuscript to BioMed Central and take full advantage of:}

- Convenient online submission

- Thorough peer review

- No space constraints or color figure charges

- Immediate publication on acceptance

- Inclusion in PubMed, CAS, Scopus and Google Scholar

- Research which is freely available for redistribution

Submit your manuscript at www.biomedcentral.com/submit
C BioMed Central 